\title{
Information Support of Management Control in Information Asymmetry and Modern Instability
}

\author{
Svitlana Kuznetsova ${ }^{1, *}$, Andriy Kuznetsov ${ }^{2}$ \\ ${ }^{1}$ Department of International Finance and Banking, Alfred Nobel University, Ukraine \\ ${ }^{2}$ Department of Economics Enterprises, Tavricesciy State Agrotechnical University, Ukraine
}

Copyright (C) 2015 Horizon Research Publishing All rights reserved.

\begin{abstract}
Information support model of management control is provided for building an integrated information system which collects detailed information about the state of the company on the strategic, tactical and operational levels of management and directions. Its construction is based on the concept of 4Ms and the pyramid of efficiency. The exact model designed for information support of management control has been formed by assessing 3 alternative models (conviction, cooperation and pragmatism) and selected on the basis of the strategy of the company, its specifics and existing features of the environment in which it functions. Taking into account the factors of instability in the formation of information support of management control for managerial decision-making it is reasonable to rely on such methods as adjustments, risk analysis and sensitivity analysis. Based on Arrow's impossibility theorem and the existing state of the management control systems regarding determination of groups of indicators, which will be monitoring effectiveness, it is expedient to introduce a dictatorial approach.
\end{abstract}

Keywords Management Control, Management Accounting, Information Support, BSC, Information Asymmetry, Methods of Instability Consideration

\section{Introduction}

Computerization of modern economy and society requires revision of the traditional approaches to management control. This is a significant change in users' information needs while making management decisions.

A fundamental role is played by the overall transition to a knowledge-based economy which is characterized by the dominance of information resources, intellectual capital and intangible assets.

Information usually means data, facts and observations, anything that extends our understanding of the object of study. The position of Akerlof [1] and Yusupov [2], who believe that human society presents an information system and its development depends on the amount of information that is perceived and transformed by its members, is considered to be interesting.

In today's economic environment characterized by inherent instability, turbulence, dynamics and, as a result, a crisis and at the same time the increasing degree of society informatization as well as levels of communication in all economic sectors, it is management control as a tool of identifying stabilization and preservation that is gaining importance.

Therefore, it can be stated with regard to the company that development of management control is defined by the quality of relevant information support. In its turn, the quality is derived from the reduction of information asymmetries and uncertainty inherent in its recipient. As it was rightly proved by George Akerlof [1], the quality and uncertainty are interrelated. Thus, the purpose of management control is to reduce information entropy (or uncertainty of unpredictable information). Reducing the information user's uncertainty determines the level of information capacity of the message. Therefore, the guarantee of the whole business efficiency is the quality of information in management control.

\section{Objectives}

Management control is effective as long as it provides an increase in company's value (share price, dividends, capital gain etc).

The problem of management control and management accounting in current economic conditions has found some coverage in some scientists' research.

Ahrens and Chapman [3] explored the ways in which ideas about the role of management accounting systems in a firm's strategy have changed in recent years.

Bhimani discussed [4] accounting and management control systems and wider structural shifts connected with the advent of digital technologies and the propose contributors analyze organizationally focused shifts occurring concomitantly alongside digital transformations in 
the economy.

Bhimani and Bromwich examined [5] the possibilities for accountants to widen their focus and become more familiar with the enterprise technology determining their organizations' cost structures and with the effects of multiple production in various locations, such as economies or diseconomies of scale.

Berry and Jarvis [6] examined business from the perspectives of economics, behavioral science, law, quantitative methods and accounting.

Burchell et al [7] seeks to contrast the roles that have been claimed on behalf of accounting with the ways in which accounting functions in practice.

Mc Grow [8] described accounting as system and procedures. Bromwich, M. et al [9] observed influences of economics in management accounting. Horváth \& Partner proposed [10] the concept of the controlling as system of assessment and information support.

Hoskin, Macve and Stone examined [11] towards understanding the historical genesis of modern business and military strategy, contemporary issues in management accounting.

The previous assessment of management control systems in 62 Ukrainian engineering companies [12] has shown that the main drawbacks of existing information support are:

1) various aspects of management control are held by individual departments, information is scattered among them which stipulates absence of the possibility of integrated operational use;

2) analysis of the company's management control is carried out with serious delays when major motivational mechanisms have already been established for the company personnel and the opportunity to influence them has been lost;

3) performance of individual business units regarding management control is usually not analyzed at all.

Malina et al [13] reported evidence on the effectiveness of the Balanced Scorecard (BSC) as a strategy communication and management-control device. This study reviewed communication and management control literatures that identify attributes of effective communication and control of strategy and offered a model of communication and control applicable to the BSC. Malina et al analyzed empirical interview and archival data to model the use and assess the communication and control effectiveness of the BSC.

The objectives of information support of modern management control in information asymmetry and instability are to provide information that focuses on decision-making in the fields of:

1) company's adaptation to the environment;

2) integration of internal company's environment;

3) company and staff identification.

Taking into account the above mentioned information, special attention should be paid to reduction of information asymmetry between staff, company management and its owners. As a result of the distribution of functions, a better-informed administrative body has more leverage on the specific situation and acts in its own interests. In addition, staff often do not have sufficient experience and are constrained with the lack of time. This information asymmetry is the reason that reduces the effectiveness of business development and quality management control. An effective mechanism for reducing information asymmetry is involving staff in the process of management control.

The use of personnel as a mechanism for reducing the information asymmetry is more effective because staff is not directly involved in management control and has direct access to all the company's assets. Therefore, in contrast to the governing body, it is interested in preventing the use of shadow schemes and supply through structures "associated" with the executive board as well as in decision-making which is effective in terms of long-term strategic business development in general.

It is also important to decrease information asymmetry between internal players (managers, employees) and players of the company's external environment (investors, partners, contractors, government, and civil society).

The goal of this research is study and build information support model of management control which collects detailed information about the state of the company on the strategic, tactical and operational levels of management and directions of activities to eliminate information asymmetry.

\section{Concept of Information Support of Management Control System}

Effective information support of management control can be achieved by building an integrated information system which collects information about the status of management control with particularization on all levels of management.

While forming a model of such informational support, it is advisable to rely on the concept of pyramid efficiency offered by McGrow, McNair, C.J., Lunch, Richard, L., Cross, Kelvin, F. [14]. According to this concept, efficiency is achieved through the company's global quality management, industrial engineering and inspection. Objectives are transmitted top-down through the management levels and performance is defined bottom-up. The pyramid of efficiency proposed by the researchers is based on considering the relationship between the total client-oriented corporate strategy, financial performance and quality indicators. The study of the outlined concept allowed claiming that it can be developed in the context of its application to designing the model of information support of management control. 


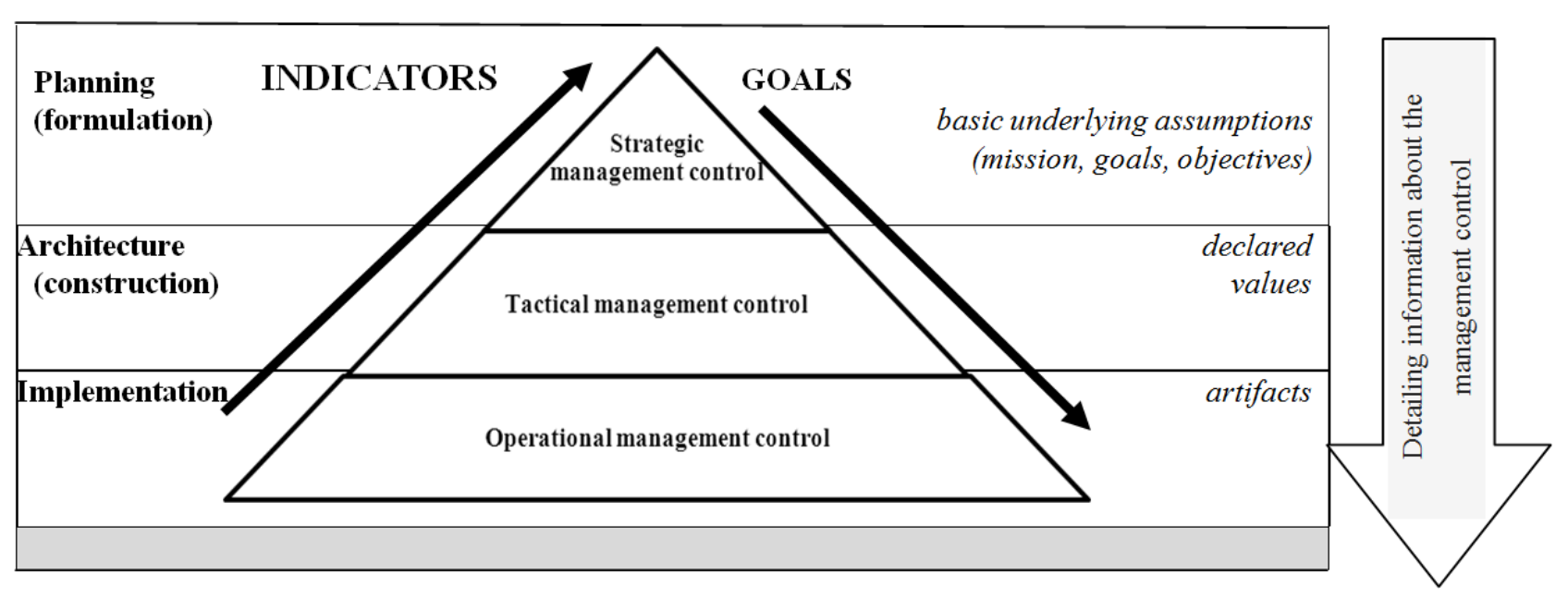

Figure 1. The concept of informational support of management control

1) measurement which involves the formation of indicators by which management control and its status can be measured;

2) management system which requires basing on a systematic approach to management control;

3) motivation which makes the use of a motivational mechanism as a management tool obligatory;

4) mindset which contributes to the formation of qualitatively new management control of the company through a change in the basic knowledge managers.

It provides detailed information on management control according to the levels of management.

Thus, at the level of strategic management there is a need for information that enables decision-making on the basic ideas of the company. Therefore, information provision at this level should be aimed at planning (formation) of management control activity.

In its turn, the level of tactical management involves construction of management control through the proclamation of values. Relevant information for decision-making should be more detailed and allow users to analyze the efficiency of the declared value as part of the management control. The level of operational management is aimed at management control implementation through visual artifacts. This leads to the need for maximizing detailed information about the management areas of the company including effectiveness of the use of the existing visual artifacts as attributes of the declared company values.

Information support of management control should include the following requirements:

1) Provided information should be useful for decision-making on management control;

2) Provided information should attract attention of managers to areas of potential risk in the management control;

3) Provided information should allow assessing the state of management control objectively.

The components of information support of management control are: 1) urgent reporting on management control of the company; 2) operational information support through monitoring the effectiveness of management control in different issues.

To form a practical mechanism for information support of management control applied by the personnel at different time intervals (year, quarter, month, decade, week, day, on-line) it is advisable to develop complex management reports.

The information provided in the reports on the management control of the company must perform the following tasks:

1) to provide informational support to managers in making strategic management decisions;

2) to develop targets and indicators of the actual management control;

3) to generate information on alternatives for selecting the most effective ways of management control;

4) to provide an information base to optimize areas of management control.

\section{Results}

\subsection{Information Support Models of Management Control}

The specific model of the company's management control system should be formed by assessing alternative models, and selected on the basis of the company strategy, its specifics and the information system of the company as well as existing features of the environment in which the company operates.

Therefore, on the foreground there is the key role of management control system as a transformer of the company strategy into concrete results. To increase the value of the company and increase its efficiency in practice there are such variants of the strategy of business development:

1) segmentation of activities (provision of advantages over competitors in the market segment (geographic, 
psychographic and demographic etc);

2) differentiation (penetration into other areas, or inclusion of new business areas in the portfolio of the company's business);

3) creation of competitive advantages;

4) use of the concept of a «perfect» company;

5) growth of its share in value added chain in comparison with competitors, suppliers and consumers of the products of the company (including creation of vertically-integrated companies);

6) orientation on the exchange activities, allocation of resources to maintain constant internal and external innovation, initiating changes of the rules of the game on the market in their favor;

7) minimization of costs.

The goal of the business (not company resources) and requirements (specifications) of the environment should be the only constraints of management control because management control must be seen as a means of solving conflicts between the goals and capabilities of the company at any given time.

It is advisable to take an approach called "alignment" which was developed by Hirschheim and Sabherwal for information systems [15] as a principle for modeling information support of management control. This approach suggests selecting 3 profiles of business strategy regulation: persuasion (regulation through leadership in business), cooperation (regulation through the partnership) and utility (regulation due to the low cost of delivery).

In relation to the management control system it is proposed to define the following models: belief, cooperation and pragmatism. The properties of each of them are systematized and presented in Table 1.

Table 1. Information support models for management control system

\begin{tabular}{|c|c|c|c|}
\hline \multirow{2}{*}{ Properties } & \multicolumn{3}{|c|}{ Information support of management control models } \\
\cline { 2 - 4 } & Convictions & Cooperation & Pragmatism \\
\hline $\begin{array}{c}\text { Focus of } \\
\text { business } \\
\text { strategy }\end{array}$ & Innovations & Analysis & Protection \\
\hline Role & Opportunistic & Comprehensive & Security \\
\hline Resources & Own & Mixed & Outsourcing \\
\hline Structuring & Decentralization & Combined & Centralization \\
\hline $\begin{array}{c}\text { Method of } \\
\text { instability } \\
\text { consideration }\end{array}$ & Risk Analysis & $\begin{array}{c}\text { Sensitivity } \\
\text { analysis }\end{array}$ & $\begin{array}{c}\text { Method of } \\
\text { adjustment }\end{array}$ \\
\hline
\end{tabular}

Targeting each of the developed models of information support of management control should be determined by the general aim of the management as a guideline which is specified in the process of development and implementation of concepts gradually approaching towards a particular goal. In accordance with each guideline of the company a concept, which is the means for achieving goals, is developed. To choose information support of the management control model which corresponds to the company's mission it is necessary to develop a specific component of the management control of a certain level, the totality of which creates the tree of the management control development, for each target.

The decisive parameter in selecting the model of information support of management control is the determined direction of its overall strategy.

If it has a direction of innovation, use of the "conviction" model is the most effective. This model involves the use of leadership as a tool for management control. Introduction of basic concepts and overall development of management control are achieved by this model due to the belief of workers and imposing declared values and artifacts. This model is based on the internal resources of the company. Accordingly, the subject of management control is the managers at all levels of management and employees. The structure of the model of information support of management control involves decentralization and transfer of leverage for each structural unit.

It should be noted that the use of this model strengthens opportunism. Opportunistic role of management control is to strengthen its impact on employees and the company as a whole at any price. In general opportunism as a direction of economic agents' behavior, which suggests keeping own interests, was studied in detail by Williamson [16]. This control is based on the need to achieve the set targets at any cost. An example of the influence of opportunism in the management control is an adverse selection problem when the potential employee is not interested in open presenting their characteristics and the CEO is not willing to demonstrate real basic idea of the company. The result of the application of this model is increase in information asymmetries both within the company and at the level of the relationship between owners and managers. Therefore, its application requires startup appropriate protective mechanisms such as improving the efficiency of information support for management control.

When directing the business strategy on analysis, that is supporting and enhancing existing positions through analysis of innovations implemented in other companies, it is advisable to choose the "cooperation" model of information support of management control which is management through partnership. According to this model it is assumed to use both internal and external resources of management such as involvement of consultants in management control to assess the state of the control. The role of the manager in this case is comprehensive and its objective is to achieve an understanding of the basic concepts of the company employees as well as support the declared values and the perception of visual artifacts. Therefore, management control should be combined (mixed) and predict the availability of appropriate managers responsible for managing this area with further decentralization of management functions in subdivisions.

When targeting the strategy at protecting existing positions, it is reasonable to use the "pragmatism" model by which management control is based on the importance and benefits. In this case, the manager acts as a protector and 
corresponding management control has a protective role for the company. The main resource for this model is external, which involves outsourcing services for management control. According to this model, it is possible to involve the external consultants, experts and controllers. Also the centralized structure with the assigned director or creation of the relevant department responsible for management control is effective. It is also possible to rest the responsibility for management control with the CEO.

\subsection{Adapting the Methods of Instability Consideration to Management Control System}

Taking into account the factors of instability in management control it is advisable to rely on appropriate methodological tools. Systematization and critical evaluation of the methods which are proposed in modern literature [11, 17, and 18] and measure the extent of instability from the standpoint of the possibility of using it in management control allowed distinguishing the following methods:

- method of adjustments;

- risk analysis;

- sensitivity analysis.

The adjustment method takes into consideration factors of instability by adding or subtracting a certain value (determined as a percentage) from indicators. In relation to the management control of the company, this method can be applied at all levels of government in order to diagnose the state of management control in all functions. The advantage of this method is certain simplicity and high speed of calculations. The disadvantage of its use is the lack of consideration of certain factors of instability and averaging the value of their influence.

Sensitivity analysis is based on evaluating the impact of possible changes (factors of instability) on the outcome that will be achieved. This method analyses the consequences of certain actions of uncertainties without further consideration of these factors as criteria for decision-making. Therefore, management control using sensitivity analysis should include evaluation of alternative results that can be obtained when making management decisions based on the impact of the factors of instability.

While using risk analysis not stable numerical values are applied but distribution of values as to the theory of probability. Therefore, the application of this method in management control allows for consideration of the impact of accidents and distribution parameters.

The overall quality of information support of management control is determined by the ability to provide information in the form of reports for:

- the subjects of external environment - external users;

- the purposes of the current planning, monitoring and evaluation;

- strategic management decisions; acceptance of administrative decisions in non-standard situations.

Reporting by the first group (external reporting) belongs to the sphere of public reports which are strictly subject to standard guidelines. Meanwhile external users are owners, investors, lenders and the public (actual or potential). Reporting by the second, third and fourth groups are the prerogative of management. These reports contain information not only about the general state of the company but also about the situation in the various segments of management. This information applies to internal users. When developing complex management reports and using them to control the efficiency of the company, there should be provided four global directions:

1) HR perspective;

2) motivational perspective;

3) stimulating perspective;

4) organizational perspective.

For each perspective it is necessary to develop and align the priorities of evaluation of management control with the position of the general strategy of the company.

\subsection{Using Arrow's Impossibility Theorem for the Selection of Management Control Indicators}

An effective mechanism for information support of management control is monitoring its effectiveness.

When monitoring the effectiveness management offer continuous tracking process of management control in order to identify its compliance with desirable economic, socio-economic and social outcomes.

As part of the development tools using which it is possible to monitor the efficiency of management control, it is advisable to analyze the achievements of scientists to evaluate effectiveness of management control. Thus, the authors identify $[19,20,21,22,23,24,25]$ not only management control and communication aspects of psychological climate in the team as evaluation parameters but also assessment of the economic efficiency of the employees of the company.

The diversity of needs of management, availability of practical management control, a number of problems (at the stage of planning, organization, implementation and control) and the effect of external and internal factors on the effectiveness of such controls create a need for forming a single integrated approach to development and implementation of the system of monitoring the effectiveness of management control.

To formulate this approach it is necessary to apply Arrow's impossibility theorem [26]. Arrow substantiated that there are no democratic functions of public welfare, which would be a link between individual preferences and social choice and also meet the requirements: 1) social welfare function is determined for each individual pair of admissible ordering, RI, R,; 2) if an alternative social state $\mathrm{X}$ is raised or lowered in order not everyone without any other 
changes with respect to $\mathrm{B}$ and $\mathrm{B}$ is preferable to other alternatives to changes in the ordering of the individual, then $\mathrm{X}$ is preferred 3) under the "social welfare function" there will be meant a process or rule that for each of the sets of individual ordering $\mathrm{R}, \ldots, \ldots, \mathrm{R}$, for alternative social states (one for each order) state corresponds to the social ordering of alternative social states, 4) social welfare function cannot be imposed, and 5) social welfare function should not be dictatorial. K. Arrow proved that the above requirements are in conflict: under no circumstances, social security system can meet all these requirements simultaneously.

Extrapolating Arrow's impossibility theorem to the company it can be argued that, under no circumstances management system can fulfill all the requirements simultaneously:

1) performance indicators for the management control are defined separately for each object of management (structural unit, geographical or commercial segment);

2 ) if the level of performance indicator (or object of control) $\mathrm{X}$ rises as compared with the indicator/object of management, and based on the indicator/ object of management it is higher than the indicator/ control object, then the level based on the indicator /control object $\mathrm{X}$ is higher than the indicator/control object;

3 ) independence of other alternatives - efficiency indicator determines the benefits of whatever action the company may not currently execute;

4) performance indicators for the management control cannot be imposed;

5) selection of the indicators of the effectiveness of management control cannot be dictatorial.

Based on evidentiary aspects of Arrow's impossibility theorem and the existing state of the management control of 62 companies of Ukraine, which is analyzed in previous study [12], while determining the system of indicators that will monitor the effectiveness of management control for the companies of Ukraine it is advisable to reject the fifth requirement that is to implement the dictatorial approach. In other words, the company must determine the official who would be responsible for taking the administrative decisions regarding the inclusion of each indicator in the system of indicators which monitor the effectiveness of management control. Giving the pivotal importance of management control as a tool for increasing the efficiency of the company the CEO shall be the respective official.

Change of this condition allows meeting other four requirements including the impossibility of imposing performance management which is counterweight towards "absolute tyranny" in evaluating management. Therefore, the use of the dictatorial approach will allow improving the efficiency of objective evaluations as, on the one hand, a management decision will be preceded by a discussion of indicators and, on the other hand, their assessment of compliance with the chosen strategy.

In general, monitoring the effectiveness of management control of business can be done by applying the following groups of indicators: financial, marketing, foreign trade, technology, property, industrial, product characteristics employment, client, time, specific, social and capitalization.

The mechanism of information support of management control should provide for the formation of information and provision of management reports which contain information on 4 levels (development of the concept of management control of the company's Strategic plan and Report on implementation of the management control of the company for 3 years; the details of the concept of management control of the company Plan and report on the development of management control for 1 year; development of tactics for the improvement of management control of the company plans and reports on the development of the management control of the company for the quarter; formulation of the operational objectives for the management control and the company's plans and reports for the month of conducting an operational task).

A large number of potential indicators can complicate the process of monitoring and reverse the results through spraying. Therefore, each company must determine for itself the priority indicators which will be implemented and monitored.

\section{Conclusions}

The study and assessment of the state of management control systems has been done and it has shown that the main disadvantages of the existing informational support are: 1) different aspects of control are handled by separate units and information is divided between them that causes the absence of the possibility of its operational complex use; 2) analysis of the company's management control is carried out with serious delays when major motivational mechanisms have already been established for the company's personnel and the opportunity to influence them has been lost; 3) effectiveness of separate structural divisions of management control, as a rule, is not analyzed at all.

In general, the key to effectiveness of business development is the quality of information support of the management control. This is determined by the level of reducing information asymmetry concerning the management control of the company between the subjects of internal (managers, employees) and external environment of the company (investors, partners, contractors, state, public). An effective mechanism of reducing the level of information asymmetry is use of the information support in the process of control of the company.

The practical use of the generated model of information support in the compilation of the proposed mechanism of the formation of immediate reporting on the management control and the basics of establishing the system of monitoring the effectiveness of management control provides the creation of the qualitative management information taking into account the specifics of the company aimed at the reduction of information asymmetry and makes the development of management control possible in 
accordance with the company's overall strategy.

\section{Acknowledgements}

The authors gratefully acknowledge the support of this research by prof. Bromwich (LSE), prof. Bhimani (LSE), and the discussions by participants of MARG-2013 conference and ACMAR -2014.

\section{REFERENCES}

[1] G. Akerlof, The Market for 'Lemons': Quality Uncertainty and the Market Mechanism, Quarterly Journal of Economics, Vol.84, No.3, 488-500, 1970

[2] R. Yusupov, History of information and philosophy of science information reality, Academic Project, Russia, 2007

[3] A.T. Chapman, Management control systems and the crafting of strategy: a practice-based view, Controlling Strategy Management Accounting and Performance Measurement, No.1, 106-124,2005

[4] Bhimani, Management accounting in the digital economy. Oxford University Press, Oxford, UKC, 2003

[5] Bhimani, M. Bromwich, Management Accounting: Retrospect and Prospect, CIMA, Elsevier, 2009

[6] Berry, R. Jarvis, Accounting in a Business Context, London, Melbourne, Madras, 1994

[7] S. Burchell, C., Clubb, A. Hopwood, A. Hughes, The roles of accounting in organizations and society, Accounting, Organizations and Society, No.5, 5-27, 1980

[8] M. Grow, Accounting: System and Procedures,- Hill Book Company. Hill Book Company, 1998 Accounting: System and Procedures./ Mc Grow.

[9] M.C. Bromwich, A. Chapman, M. Hopwood, Economics in Management Accounting, Handbook of Management Accounting Research, No.1, 139-164, 2006

[10] IFUA, Horváth \& Partner, Das Controlling konzept: Der Weg zu einem wirkungsvollen Controlling system, Horváth und Partner (Stuttgart) Dt. Taschenbuch-Verlag, 2003

[11] K. Hoskin, R. Macve, J. Stone, Accounting and strategy: Towards understanding the historical genesis of modern business and military strategy, contemporary issues in management accounting, Oxford, Oxford University Press, 166-197, 2006
[12] S. Kuznetsova, A. Kuznetsov, The Perspective of information Management Accounting in Ukraine: The synergistic Approach and Arrow's impossibility theorem, World Journal of Social Sciences, 4, 1: 140 - 153, 2014

[13] M. Malina, F.H. Selto, Communicating and Controlling Strategy: An Empirical Study of the Effectiveness of the Balanced Scorecard, Journal of Management Accounting Research, No.13, 47-56, 2001

[14] M. Grow, M. Nair, C.J., Lunch, L. Richard, F. Kelvin, Do financial and nonfinancial performance measures have to agree?, Management Accounting, No.11, 68-92, 1990

[15] R. Hirschheim, R. Sabherwal, Detours in the Path toward Strategic Information Systems Alignment, California Management Review, Vol.44, No.1, 87-108, 2001

[16] Williamson, Behavioral assumptions of modern economic analysis, THESIS, No.3, 41-49, 1993

[17] K. Bleicher, Organisation, Strategien, Strukturen, Kulturen, Aulf. Wiesbaden, 1991

[18] M. Alavi, T. D. Kayworth, E. Leidner, An Empirical Examination of the Influence of Organizational Culture on Knowledge Management Practices, Journal of Management Information Systems Vol.22, No.3, 191-224, 2005-2006

[19] J. Baetge, Bilanzen, Publishing House Accounting, Moscow, 2000

[20] Caldwell, Missteps, miscues: Business Reengineering Failures Have Cost. Corporations Billions, and Spending is Still on the Rise, Information Week, No.1, 50-60, 1990

[21] H. Chesbrough, R. Rosenbloom, The role of business model in capturing value from innovation: evidence from Xerox Corporation's technology spinoff companies, Industrial and Corporate Change, 529-555, 2002

[22] H. Courtney, J. Kirkland, Strategy under uncertainty, Harvard Business Review, Vol.75, No.6, 66-89, 1997

[23] Rappaport, Creating shareholder value: The new standard for business performance, Free Press, New York, 1986

[24] Solomons, The polarization of accounting, Journal of Accountancy, Vol.146, No.5, 65-72, 1978

[25] Stephen, T. Hansen, A theoretical analysis of the impact of rolling budgets, activity-based budgeting and beyond budgeting, European Accounting Review, Vol.20, No.2, 289-319, 2011

[26] K., J. Arrow, Social Choice and Individual Values, John Wiley \& Sons, Inc., New York, London, Sydney, 1963 